\title{
The Preparation and Property Research of Bismuth Oxide Nanospheres
}

\author{
Lili Ding, Qian Zhao, Jingli Zhu, Zengjie Fan, Bin Liu* \\ School of Stomatology, School of Nuclear Science and Technology \\ Lanzhou University, \\ Lanzhou 730000, P. R. China \\ Lili Ding: dinglililzukq@163.com. Bin Liu:liubkq@lzu.edu.cn
}

\begin{abstract}
Nanomaterials are a new option to successfully treat the multiresistant microorganisms. The as-prepared bismuth oxide with the optimal concentration exhibits stronger antibacterial abilities than others. Meanwhile, it exhibits well biocompatibility. In one word, the present approach can shed new light on designing of antibacterial material like bismuth oxide with promising applications in biological sciences.
\end{abstract}

Keywords-bismuth oxide $\quad\left(\mathrm{Bi}_{2} \mathrm{O}_{3}\right) ; \quad$ preparation;
antibacterial; cytocompatibility

\section{- I. INTRODUCTION}

Recently, Nanostructured materials have attracted considerable research interest because of their great potential in diverse fields of magnetic separation, biomedicine, catalysis and biological sciences [1]. Nanomaterials are a new option to successfully treat the multiresistant microorganisms. The metal ions of antibacterial products contact with bacteria can cause microbial inherent component damage or dysfunction. It is well-known that zinc oxide nanoparticles $(\mathrm{nZnO})$ possesses antibacterial activity and currently is used in many cosmetic materials [2]. The nano-silica silver nanocomposite (NSAgNC) is as antibacterial effect on gram-negative bacteria viz. Pseudomonas aeruginosa and Escherichia coil has been investigated, however, the studies further demonstrated the down regulation of protein and fragmentations of DNA expression in NSAgNC treated cells leading to the cell death [3]. Recently, it was demonstrated that the bactericidal activity of zero-valent bismuth colloidal nanoparticles inhibited the growth of Streptococcus mutans. Typically, bismuth is found as bismite (bismuth oxide $\left[\mathrm{Bi}_{2} \mathrm{O}_{3}\right]$ ), bismuthite (bismuth carbonate) and bismuthinite (bismuth sulfide), in medicine, bismuth, has been employed as an antidiarrheal to treat vomiting, stomach, and pain nauseas. $\mathrm{Bi} 2 \mathrm{O} 3$ shows a distinctive polymorphism, including the following solid state phases: $\alpha-\mathrm{Bi}_{2} \mathrm{O}_{3}, \beta$ $\mathrm{Bi}_{2} \mathrm{O}_{3}, \gamma-\mathrm{Bi}_{2} \mathrm{O}_{3}, \delta-\mathrm{Bi}_{2} \mathrm{O}_{3}$, and the recently characterized $\varepsilon-$ $\mathrm{Bi}_{2} \mathrm{O}_{3}$. The $\alpha-\mathrm{Bi}_{2} \mathrm{O}_{3}$ is the most thermodynamically stable phase at room temperature and pressure [4]. So, under standard reaction conditions in aqueous solutions, the $\alpha$ $\mathrm{Bi}_{2} \mathrm{O}_{3}$ is formed, a poorly water-soluble specie that carries surface hydroxyl groups, $\alpha-\mathrm{Bi}_{2} \mathrm{O}_{3}$ is a basic oxide and its $\mathrm{Bi}-\mathrm{O}$ bonds are predominantly ionic; it is a p-type semiconductor material [5]. $\mathrm{Bi}_{2} \mathrm{O}_{3}$ is a derivative of great technological importance, and it is used in the manufacture of glass and ceramic products, and also, as catalyst in the oxidation of hydrocarbons. It is widely used in applications, such as microelectronics, and sensor and optical technology [6-8]. Recently, the $\mathrm{Bi}_{2} \mathrm{O}_{3}$ porous nanospheres demonstrated outstanding performance in visible-light-driven photocatalysis for $\mathrm{Cr}$ (VI) and organic dye removal, inactivation of Gram-negative and Grampositive bacteria, as well as template-synthesis for fabrication of bismuth related hollow nanostructures [9]. It is important to emphasize that we did not find any report concerning cytotoxicity of common bismuth nanostructured derivatives. And it is necessary to determine the possible toxicity of $\mathrm{Bi}_{2} \mathrm{O}_{3}$ NPs in human fibroblasts cultures and analyze their potential use in humans.

This paper reports the synthesis of $\mathrm{Bi}_{2} \mathrm{O}_{3}$ nanospheres and antibacterial test and cytocompatibility evaluation of as obtained $\mathrm{Bi}_{2} \mathrm{O}_{3}$ nanospheres. 


\section{- II. EXPERIMENTS}

\section{A. Materials}

$\mathrm{Bi}\left(\mathrm{NO}_{3}\right)_{3} \cdot 5 \mathrm{H}_{2} \mathrm{O}$ was purchased from Tianjin Chemical Reagent Co., Ltd. $\mathrm{HNO}_{3}$ was purchased from Xilong Chemical Co., Ltd. PEG-4000 were purchased from Sinopharm Chemical Reagent Co., Ltd. $\mathrm{NaOH}$ was obtained from Tianjin Chemical Reagent Co., Ltd. ethyl alcohol was obtained from Tianjin Chemical Reagent Co., Ltd. Dulbecco's modified Eagle's medium (DMEM) and Dimethyl sulfoxide (DMSO) were purchased from Gibco. Trypsin-EDTA solution and MTT, guaranteed reagent were supplied by Sigma. Fibroblastic cells (L929) were provided by the Fourth Military Medical University. Ultrapure water was used for rinsing and as the solvent as well.

\section{B. The Preparation of $\mathrm{Bi}_{2} \mathrm{O}_{3}$ Nanospheres}

All chemicals used in the experiment were analytical reagents and were used as received. In a typical procedure, $24.25 \mathrm{~g} \mathrm{Bi}\left(\mathrm{NO}_{3}\right)_{3} \cdot 5 \mathrm{H}_{2} \mathrm{O}$ was dissolved by $30 \mathrm{~mL} 0.05 \mathrm{~mol} \mathrm{~L}^{-1} \mathrm{HNO}_{3}$ to obtain transparent aqueous solution, then $20 \mathrm{~mL}$ polyethylene glycol (PEG-4000) was added as dispersant. Then $50 \mathrm{~mL} 4 \mathrm{~mol} \mathrm{~L}^{-1} \mathrm{NaOH}$ aqueous solution was quickly poured into the prepared solution under vigorous stirring, which immediately resulted in the formation of yellowish precipitates in the beaker. The as-produced precipitates were filtered after kept at $90^{\circ} \mathrm{C}$ for $2 \mathrm{~h}$ under stirring, then washed with alcohol and ultrapure water for several times and dried at $60^{\circ} \mathrm{C}$ in a vacuum drier to obtain the yellow $\mathrm{Bi}_{2} \mathrm{O}_{3}$ samples. The as-produced $\mathrm{Bi}_{2} \mathrm{O}_{3}$ powders were milled by ball mill with the 400 rotary velocities for $400 \mathrm{~min}$ to obtain final powders.

$\mathrm{Bi}_{2} \mathrm{O}_{3}$ powder was dissolved in distilled water and stirred until complete dissolution, then different concentrations of suspension liquid $(0.25,0.5,1,1.5 \mathrm{mg}$ $\mathrm{mL}^{-1}$, respectively) were obtained.

\section{Characteristics}

The morphology of as-synthesized samples was observed with a scanning electron microscope (SEM, JEOL JSM-6701F) at $5.0 \mathrm{kV}$ and a transmission electron microscope (TEM, JEOLJEM -2010). The structure and phase composition of as-synthesized samples were characterized by X-ray diffraction (XRD, Rigaku D/Max2400 diffractometer, $\mathrm{CuKa} 1 / 4 \lambda=1.54056 \AA$ ).

\section{Antibacterial Activity Measurement}

The bacteria (S. aureus) used were cultured in the Luria Bertani (LB) liquid medium at $37^{\circ} \mathrm{C}$ for $24 \mathrm{~h}$. Before the antibacterial test, all the samples and materials in the experiments were sterilized at $121^{\circ} \mathrm{C}$ for $20 \mathrm{~min}$. The antibacterial activities of $\mathrm{Bi}_{2} \mathrm{O}_{3}$ samples towards $\mathrm{S}$. aureus were evaluated by colony counting methods. The colony counting test was performed by mixed $2 \mathrm{~mL} 10^{6}$ $\mathrm{CFU} \mathrm{mL} \mathrm{mL}^{-1}$ diluted bacteria and $2 \mathrm{~mL} \mathrm{Bi}_{2} \mathrm{O}_{3}$ samples $(0.25$, $0.5,1,1.5 \mathrm{mg} \mathrm{mL}^{-1}$ ) into tubes, then the mixtures were incubated for $4 \mathrm{~h}$ at $37^{\circ} \mathrm{C}$ with shaking at $300 \mathrm{rpm}$. Then, $0.1 \mathrm{~mL}$ of the mixtures were diluted into $10^{-6}, 10^{-7}, 10^{-8}$, and then plated onto LB agar plates and the number of the colonies was counted after incubation for $24 \mathrm{~h}$ at $37^{\circ} \mathrm{C}$.

\section{E. Fibroblastic Cells Culture}

In this research we used L929 cells to analyze the cytotoxic effect of Bi2O3 NPs. The fibroblastic cells were grown in DMEM containing 10\% fetal bovine serum, 4.5 $\mathrm{g} / \mathrm{L}^{-1}$ glucose, $\quad 2 \mathrm{mM} \quad$ L-glutamine, and $1 \%$ antibiotic/antimycotic solution. The cells were kept under sterile conditions at $37^{\circ} \mathrm{C}$ and $5 \% \mathrm{CO}_{2}$. The media were refreshed every day until the cells reached confluence.

\section{F. Cellular Viability by MTT Assay}

Cell viability was determined by the MTT assay, which is based on the reductive cleavage of MTT to formazan by mitochondrial dehydrogenase of living cells [10]. All the samples and materials in the experiments were sterilized at $121^{\circ} \mathrm{C}$ for $20 \mathrm{~min}$, and then placed into a 24-well plate and seeding density was $2 \times 10^{4}$ cells $\mathrm{mL}^{-1}$ each well. At a set period of time (1, 2, 3 days), each well was infused with $100 \mu \mathrm{L}$ MTT solution, then cultured for 4h. The upper solvent was removed, and the blue formazan reaction product was dissolved by adding DMSO $(200 \mu \mathrm{L})$ after culturing. The ultimate dissolvable solution was transferred into a 96-well plate, and then its absorbance of $490 \mathrm{~nm}$ was recorded with a microplate reader. The data of three parallel experiments were averaged. The cellular survival rate were calibrated by blank and control groups. To this end, culture media were added only into the blank group, while the control group 
was designed to cells and culture media without samples. The optical density (OD) values of the blank, control, and experimental groups are enciphered as OD bla, OD con, and $\mathrm{OD}_{\text {exp }}$; and the cellular survival rates are calculated as Survival Rate $=\left(\mathrm{OD}_{\text {exp }}-\mathrm{OD}\right.$ bla $) /(\mathrm{OD} \text { con-OD bla })^{*} 100 \%$ (1)

Results are expressed as mean \pm standard deviation and are analyzed with the Student's t-test.

\section{- III. RESUlts AND DisCUSSION}

\section{A. Characterization of $\mathrm{Bi}_{2} \mathrm{O}_{3}$}

Figure $1 \mathrm{~A}$ shows the morphology of $\mathrm{Bi}_{2} \mathrm{O}_{3}$ without milling, the SEM image shows stick crystals with an average length of $15 \mu \mathrm{m}$. Figure $1 \mathrm{~B}$ shows typical XRD patterns of the as-synthesized $\mathrm{Bi}_{2} \mathrm{O}_{3}$ without milling, all the diffraction peaks are well indexed to $\mathrm{Bi}_{2} \mathrm{O}_{3}$ (JCPDS 76-2478), indicative of the high purity of $\mathrm{Bi}_{2} \mathrm{O}_{3}$. It indicates well-crystallized $\mathrm{Bi}_{2} \mathrm{O}_{3}$ can be successfully produced via the solution-based approach without having resort to the high-temperature calcination process as have to be taken by the traditional methods. Figure $1 \mathrm{C}$ shows the morphology of milled $\mathrm{Bi}_{2} \mathrm{O}_{3}$, the $\mathrm{SEM}$ image illustrates that final $\mathrm{Bi}_{2} \mathrm{O}_{3}$ powders are composed of largescale uniform solid $\mathrm{Bi}_{2} \mathrm{O}_{3}$. TEM image (Figure 1D) further demonstrates the $\mathrm{Bi}_{2} \mathrm{O}_{3}$ nanospheres with an average diameter of $350 \mathrm{~nm}$.

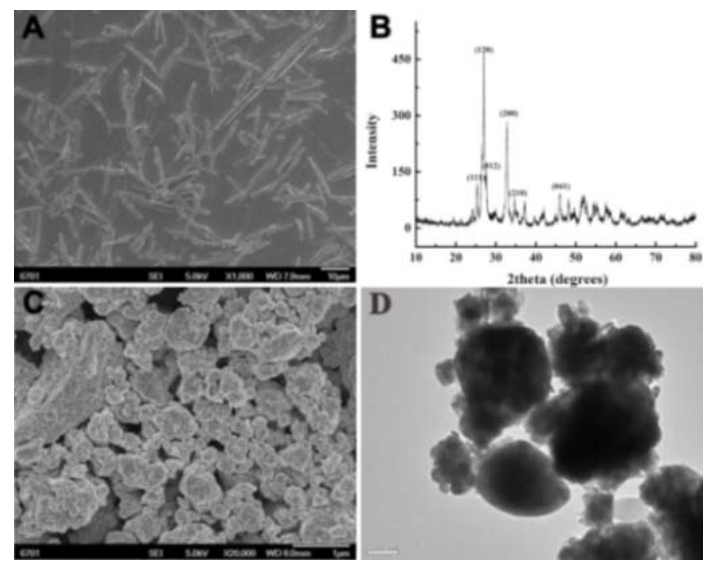

Figure 1. The Characterization of $\mathrm{Bi}_{2} \mathrm{O}_{3}$

\section{B. Antibacterial Performance}

To explore the possible antimicrobial activity of $\mathrm{Bi}_{2} \mathrm{O}_{3}$ NPs, their effect on S. aureus growth is determined. Figure 2 shows the images of antimicrobial activity of
$\mathrm{Bi}_{2} \mathrm{O}_{3}$ NPs, and Table I shows the activity of the colony. The results show that $1.5 \mathrm{mg} \mathrm{mL}^{-1} \mathrm{Bi}_{2} \mathrm{O}_{3}$ NPs reduce the number of $\mathrm{S}$. aureus by $45 \%$, in comparison with control without $\mathrm{Bi}_{2} \mathrm{O}_{3}$. This result is very important because it demonstrates the effectiveness of the nanostructured material. The mechanism of the antimicrobial activity of inorganic NPs is not completely understood, and their precise mechanism of action against bacteria remains to be fully elucidated. It has been shown that positive charges on the metal ion are critical for the antimicrobial activity, allowing for the electrostatic attraction between a negatively charged cell membrane and the positively charged NPs.

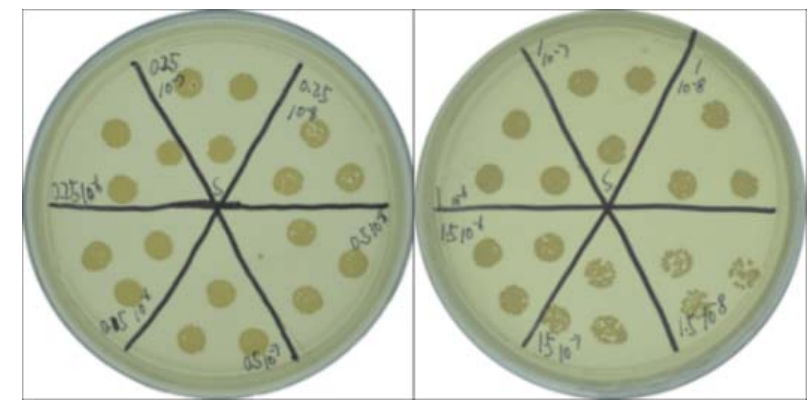

Figure 2. Photographs showing the antibacterial activity of $\mathrm{Bi} 2 \mathrm{O} 3$ NPs (S. aureus)

TABLE I. The Activity of The S. Aureus of $\mathrm{BI}_{2} \mathrm{O}_{3} \mathrm{NPs}$

\begin{tabular}{|c|c|}
\hline $\left.\mathrm{Bi}_{\mathbf{2}} \mathbf{O}_{\mathbf{3}} \mathbf{( m g ~ m L}^{-\mathbf{1}}\right)$ & Activity of the colony (\%) \\
\hline 0.25 & 88.93 \\
\hline 0.5 & 88.14 \\
\hline 1 & 86.27 \\
\hline 1.5 & 54.88 \\
\hline
\end{tabular}

C. MTT Assay

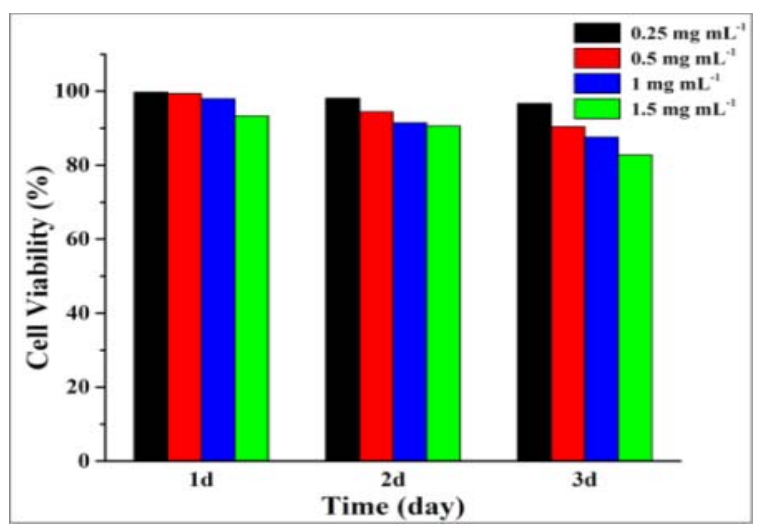

Figure 3. Cellular proliferation analysis, the cells were respectively 
incubated for 1,2 , and 3 days with $\mathrm{Bi}_{2} \mathrm{O}_{3} \mathrm{NPs}$

MTT assay is one of the methods commonly used to assess biocompatibility of materials. L929 fibroblasts were seeded directly in 96-well plates, and incubated for 1, 2, 3 days, respectively, and their viability were assessed by MTT assay. As shown in Figure 3, the Bi2O3 NPs do not promote cytotoxic effects in the L929 cells at 24 hours of exposure compared with the cells without NP. The cells looked very similar in the presence or absence of Bi2O3 NPs. These results suggest the absence of cytotoxicity by $\mathrm{Bi} 2 \mathrm{O} 3 \mathrm{NPs}$, under our experimental conditions.

\section{- IV. Conclusions}

In conclusion, $\mathrm{Bi}_{2} \mathrm{O}_{3}$ NPs of $350 \mathrm{~nm}$ average size have an antimicrobial activity inhibiting the growth of $\mathrm{S}$. aureus. Additionally, our results suggest that the $\mathrm{Bi}_{2} \mathrm{O}_{3}$ NPs, under the experimental tested conditions and concentrations, do not exhibit cytotoxicity. The present approach can shed new light on designing of antibacterial material like bismuth oxide with promising applications in biological sciences.

\section{ACKNOWLEDGMENTS}

The authors would like to acknowledge the financial support form the National Natural Science Foundation of China (Grant Nos. 81571829) and the Fundamental Research Funds for the Central Universities (Grant Nos. lzujbky-2015-35).

\section{REFERENCES}

[1] J. Padmanabhan, and T.R. Kyriakides, "Nanomaterials, Inflammation, and Tissue Engineering," Wiley Interdisciplinary Reviews: Nanomedicine and Nanobiotechnology, 2015, vol. 7, pp. 355-370.

[2] P.T. Kumar, V.K. Lakshmanan, T.V. Anilkumar, C. Ramya, A.G. Unnikrishnan, S.V. Nair, and R. Jayakumar, "Flexible and microporous chitosan hydrogel/nano $\mathrm{ZnO}$ composite bandages for wound dressing: in vitro and in vivo evaluation," Acs Appl. Mater. interfaces, 2012, vol. 4, pp. 2618-2629.

[3] T. Parandhaman, A. Das, B. Ramalingam, D. Samanta, T.P. Sastry, A.B. Mandal, and S.K. Das, "Antimicrobial behavior of biosynthesized silica-silver nanocomposite for water disinfection: A mechanistic perspective,” J. Hazard. Mater. 2015, vol. 290, pp. 117 126.

[4] T.K. Tseng, J. Choi, D.W. Jung, M. Davidson, and P.H. Holloway, "Three-dimensional self-assembled hierarchical architectures of gamma-phase flowerlike bismuth oxide," ACS Appl. Mater. Interfaces, 2010, vol. 2, pp. 943-946.

[5] C.F. Guo, J. Zhang, T. Ye, and Q. Liu, "A general strategy to superstructured networks and nested self-similar networks of bismuth compounds," Acs Nano, 2012, vol. 6, pp. 8746-8752.

[6] B. Sarma, J.A. Lurovitzki, Y.R. Smith, S.K. Mohanty, amd M. Misra, "Redox-induced enhancement in interfacial capacitance of the titania nanotube/bismuth oxide composite electrode," Acs Appl. mater. interfaces, 2013, vol. 5, pp. 1688-1697.

[7] Y. Li, M.A. Trujillo, E. Fu, B. Patterson, L. Fei, Y. Xu, S. Deng, S. Smirnov, and H. Luo, "Bismuth Oxide: A New Lithium-Ion Battery Anode," Journal of materials chemistry. A, Materials for energy and sustainability, 2013, pp. 1-5, DOI: 10.1039/C3TA12655B

[8] J.Z. Marinho, R.A.B. Silva, T.G.G. Barbosa, E.M. Richteret, and R. A.A. MuÇoz, "Graphite-Composite Electrodes Bulk-Modified with (BiO)2CO3 and Bi2O3 Plates-Like Nanostructures for Trace Metal Determination by Anodic Stripping Voltammetry," Electroanalysis, 2013, vol. 25, pp. 765-770.

[9] Q. Fan, Z. Huiping, L. Guangfang, Y. Hao, L. Ju, W. Runming, L. Yunling, H. Juncheng, S. Hongzhe, and C. Rong, "Size-tunable fabrication of multifunctional $\mathrm{Bi} 2 \mathrm{O} 3$ porous nanospheres for photocatalysis, bacteria inactivation and template-synthesis," Nanoscale, 2014, vol. 6, pp. 5402-5409.

[10]Z. Fan, J. Wang, Z. Wang, H. Ran, Y. Li, L. Niu, P. Gong, B. Liu, and S. Yang, "One-pot synthesis of graphene/hydroxyapatite nanorod composite for tissue engineering," Carbon 2014, vol. 66, pp. $407-416$. 